November 2016

"Product design and decision rights in vertical structures"

Pierre Dubois and Bruno Jullien 


\title{
Product design and decision rights in vertical structures
}

\author{
Pierre Dubois* $\quad$ Bruno Jullien ${ }^{\dagger}$
}

15 September 2016

\begin{abstract}
The paper argues that the emergence of private labels can be partially explained by the new information technologies available at the retail level. In our approach, the owner of a brand has "decision rights" on product design, while the details of the production and distribution are left to contractual negotiation. Manufacturers have privileged information about the cost of improving quality, while distributors have private information on the impact of quality on demand. We show that ownership of the brand should be allocated to the party with a relative informational advantage. In particular, if the information of the distributor improves due to a technological shock on data collection and information management, it may become optimal for the distributor to introduce its own brand, rather than to distribute a manufacturer's brand.
\end{abstract}

Keywords: store brand, private label, asymmetric information, vertical structures, product design, decision rights

\footnotetext{
*Toulouse School of Economics, University of Toulouse Capitole, pierre.dubois@tse-fr.eu

†Toulouse School of Economics, CNRS, bruno.jullien@tse-fr.eu
} 


\section{Introduction}

The development of distributor brands over the past decade has raised several issues concerning the notion of brand ownership. Several factors may contribute to explain why large distributors have decided to develop their own brands (see the survey of Berges-Sennou, Bontems and Réquillart, 2004). For instance, well established distributors with large distribution networks may leverage their position by developing reputation effects over a large range of products. This incentive to intervene as a producer may be reinforced in contexts where concentration is high at the upstream level, because the distributor controlling its own brand increases its bargaining position in a negotiation with dominant producers. ${ }^{1}$ Actually, Scott Morton and Zettelmeyer (2004) show evidence of the positive correlation between private label introduction and the market share of leading national brands. ${ }^{2}$ Notice however that while distributors have developed brands under their name for mass consumption goods, or standardized products, they also have opted for the creation of new brands with an initially unknown name. This is particularly true for high quality brands. Clearly while the distributors position matters for the promotion of new brands, it is not clear why it is more profitable to create and promote its own brand, rather than promoting an independent brand under a long term agreement. This remark is reinforced by the fact that the bargaining position of the producer of the new brand would be small since the distributor needs not rely on main incumbents for production.

In this paper we wish to stress an aspect which is complementary and provides some light on the economics of distributor brands, namely the interaction between product design and brand ownership under incomplete contracting. In an incomplete contract setting, brand ownership allocates various decision rights to the owner, and in particular the right to decide on the design of product characteristics (Grossman and Hart, 1986). By owning the brand, a distributor can effectively control the evolution of the products under a particular brand.

\footnotetext{
${ }^{1}$ Contributions along this line include Comanor and Rey (2000), Chintagunta et al. (2002), Kadiyali et al. (2000), Gabrielsen and Sorgard (2007), Meza and Sudhir (2010).

${ }^{2}$ See also Bontemps, Orozco and Réquillart (2008) for a similar conclusion using the price level of national brands.
} 
In this context, answering the question of whether the distributor would more profitably distribute its own brand rather than promote a brand owned at the upstream levels amounts to identifying the potential inefficiencies and conflicts that may arise in the product design process.

We then develop on the fact that, in an optimal relationship, the agent with the most relevant information should be allocated the right to decide on the evolution of the products characteristics. ${ }^{3}$ Notice that the development of computerized technologies has changed the balance on this respect in a dramatic way, as distributors have now access to fast, reliable and essential information through sales records, as well as the ability to treat this huge data. The idea demonstrated below is that the better informed party should be the one who chooses the characteristics of the product, a decision that belongs to the owner of the brand. Thus a shift in the information structure can justify a shift in the ownership of brands (with an idea similar to Schmalensee, 1982, that the informational advantage is used in the design of products).

Another aspect that one should bear in mind is that there may be a conflict of interest between large producers and distributors that can hardly be resolved at the development stage. Producers and distributors do not face the same objective for two reasons. First, distributors may be more concerned about the potential cannibalization of competing brands by one brand, as they distribute several brands. Second the markets are not the same, as large producers serve several markets through several distributors. While contracts help to resolve these issues concerning prices and marketing, this is more problematic at the development stage. In this context, a distributor may prefer to develop its own brand if it appears that the choices of large producers in terms of product design are too far from their needs.

In the article we present a model of vertical structure with bilateral asymmetric information (section 2). We analyze successively the case where the distributor owns the brand and

\footnotetext{
${ }^{3}$ The view that an organization may "delegate" decisions to informed party is developed by Dessein (2002), among others.
} 
designs the product (section 3) and the case where the producer owns the brand (section 4). In section 5, we compare the aggregate profit of the vertical structure under the two ownership structures. Section 6 discusses a variant in which the bargaining power and the ownership do not coincide. The last section concludes.

\section{A base model}

We consider a distributor and a producer of some product, who have different information about the cost and the demand for such a product. This difference in information may lead to different choices in terms of product design. The distributor is the sole distributor in the area and the producer the sole producer. They produce/distribute a branded product, where the brand may belong to the distributor or the producer. Expected demand is $D(p-\alpha x)$ where $x \in \mathbb{R}$ is the product characteristic - referred to as quality - and $\alpha$ is a demand shifter. The distributor gross profit is $p D(p-\alpha x)$, where the price is normalized for distribution cost. The inverse of $D$ is denoted $P$ so that the retail price is $p=P(Q)+\alpha x$.

A quantity $Q$ of quality $x \geq 0$ can be produced by the producer at a production cost $C(Q, x, \beta)=c Q+\phi(\beta, x)$. Hence, the unit variable cost is independent of quality, while there is a fixed cost that varies with the product characteristics (as Mills, 1995, does for national brands versus private labels ${ }^{4}$ ) and depends on the producer's type $\beta .^{5}$ Thus we assume that the main cost for the producers is caused by the need to reshape the production line so as to adjust to the new product design. Once this is done the unit cost is basically the same for all levels of quality. ${ }^{6}$

The informational asymmetry comes from the fact that the distributor privately knows

\footnotetext{
${ }^{4}$ Contrary to Mills (1995) who justifies that the production of national brands involves a higher fixed cost due to advertising, here we do not impose the ad hoc assumption that private labels would not incur a fixed cost but assume that the fixed cost is related to quality $(x)$ which implies the same correlation between fixed cost national brand versus private label as for Mills (1995) given that he considers that national brands are of better quality than private labels.

${ }^{5}$ In what follows, some results depend on the fact that the marginal cost is known. It could depend on $x$ also with no changes in the main conclusions.

${ }^{6}$ An alternative interpretation is that the fixed cost is an opportunity cost supported by the producer, due the effect of the quality distributed on his profits on other markets.
} 
the demand shifter $\alpha$, while the producer privately knows the cost parameter $\beta$. For conciseness, we assume that the demand shifter $\alpha$ can take only two values, $\alpha_{1}$ or $\alpha_{2}$, where $\alpha_{1}<\alpha_{2}$, and the cost parameter $\beta$ can take only two values, $\beta_{1}$ or $\beta_{2}$, where $\beta_{1}<\beta_{2}$. We denote by $f\left(\alpha_{i}\right)$ the probability that $\alpha=\alpha_{i}$ and by $g\left(\beta_{i}\right)$ the probability that $\beta=\beta_{i}$. The vector of information $(\alpha, \beta)$ can thus take four values $\left\{\alpha_{i}, \beta_{j}\right\}, i=1,2, j=1,2$. Information is soft and therefore cannot be transmitted. Demand and cost functions are supposed to be twice differentiable and to verify:

i) $Q P(Q)$ is concave and $P(0)$ is large.

ii) $\phi(\beta, x)$ is increasing and convex in $x, \phi(\beta, 0)=\frac{\partial \phi}{\partial x}(\beta, 0)=0$ and $\lim _{x \rightarrow+\infty} \phi(\beta, x)=+\infty$.

iii) $\Delta(x) \equiv \phi\left(\beta_{2}, x\right)-\phi\left(\beta_{1}, x\right)$ is positive and increasing for $x>0$.

The first condition ensures that the optimal quantity is unique and positive. The second condition ensures that it is optimal to choose a positive quality. The last one expresses that the technology parameter $\beta$ shifts the marginal cost of raising quality. We also assume that $\phi$ is convex enough so that an interior solution always exists for the product design stage (profits are strictly quasi-concave in $x$ ). These assumptions simply mean that the parameter $\beta$ is an index of efficiency of the firm in the fixed cost of production (the higher the lower the fixed cost) and that the inverse demand function is not too convex.

If the information $(\alpha, \beta)$ were verifiable and the parties were able to sign a complete contract on the product characteristic, the quantity and the wholesale price, then the industry profit maximizing production and design would be implementable. Similarly an integrated monopoly could take advantage of all information. Denote $Q^{m}(\alpha, x)$ the (full information) integrated monopoly quantity for given quality $x$, it maximizes the (variable) integrated monopoly profit:

$$
\Pi^{m}(\alpha, x) \equiv \max _{Q}(P(Q)+\alpha x-c) Q
$$

The monopoly quantity is increasing in $\alpha$ and $x$, and characterized by the well known 
condition

$$
\frac{P\left(Q^{m}(\alpha, x)\right)+\alpha x-c}{\left.P\left(Q^{m}(\alpha, x)\right)\right)}=\frac{1}{\varepsilon\left(Q^{m}(\alpha, x)\right)}
$$

where $\varepsilon(Q)=-\frac{P(Q)}{Q P^{\prime}(Q)}$.

The integrated monopoly total profit is then

$$
V^{M}(\alpha, \beta) \equiv \max _{x}\left\{\Pi^{m}(\alpha, x)-\phi(\beta, x)\right\}
$$

which is obtained for a quality level $x^{M}(\alpha, \beta)$ solution of the first-order condition

$$
\alpha Q^{m}\left(\alpha, x^{M}(\alpha, \beta)\right)=\frac{\partial \phi}{\partial x}\left(\beta, x^{M}(\alpha, \beta)\right)
$$

and thus gives a quantity solution $Q^{M}(\alpha, \beta) \equiv Q^{m}\left(\alpha, x^{M}(\alpha, \beta)\right)$. Notice that under our assumptions, the profit maximizing quality $x^{M}(\alpha, \beta)$ is strictly positive for all $(\alpha, \beta)$.

We wish to contrast the situation where ownership belongs to the upstream producer to the situation where it belongs to the distributor. The owner of the brand is assigned the right to decide on all variables that are related to the product: the parameter $x$, and whether the good is distributed or not. In the context of a brand, we assume that the ownership provides also bargaining power. ${ }^{7}$ Typically, we see the situation as follows. The distributor has no brand, while the producer is a large well known brand producer. Then the producer has a large bargaining power as it bargains on the distribution of his product and there are no existing alternatives. Only the distributor can provide an alternative by creating its own brand. This is a long-run decision. Then the distributor stops the distribution of the national brand and introduces his brand. He then turns to the producer to produce the brand. Here the negotiation is only on the production of the product, where the producer has less bargaining power. To complete the analysis, we shall also examine the case where ownership only affects the right to design the product, and the bargaining power remains to the distributor in any case.

We consider the following timing for the game between the producer and the distributor.

\footnotetext{
${ }^{7}$ As we will see, this assumption facilitates the analysis, although ultimately we may wish to separate the
} right to decide on the products characteristics and the bargaining power. 
1. The distributor learns $\alpha$, the producer learns $\beta$.

2. The owner chooses $x$, which is publicly observed.

3. The owner proposes a contract $(Q, T)$ where $Q$ is production and $T$ a transfer from the distributor to the producer.

4. Production takes place and profits are realized.

The respective profits are $\Pi_{D}=Q(P(Q)+\alpha x)-T$ for the distributor, and $\Pi_{P}=$ $T-c Q-\phi(\beta, x)$ for the producer. Notice that the quality decision takes place before the contracting stage, reflecting the fact that product design decisions are revised less frequently than prices and quantities.

\section{The distributor owns the brand}

Consider the case where the distributor is the owner of a brand. The distributor chooses $x$ and proposes a cost reimbursement contract to the producer. Given that the variable production cost is known, we can see the contract as follows. First, the distributor sets a wholesale price $w=c$, then he proposes a fixed payment $F$ in exchange of production of positive quality $x$. Thus $T=F+c Q$. Faced to such a contract, the producer accepts to produce if the fixed payment $F$ covers his fixed costs $\phi(\beta, x)$. Clearly, with only two levels of fixed cost, it is optimal to set a fixed payment either at $F=\phi\left(\beta_{2}, x\right)$ or at $F=\phi\left(\beta_{1}, x\right)$. In the latter case, the producer of type $\beta_{2}$ turns down the offer and the product is not produced. ${ }^{8}$ The distributor then obtains

$$
\begin{array}{r}
(P(Q)+\alpha x-c) Q-\phi\left(\beta_{2}, x\right) \text { if } F=\phi\left(\beta_{2}, x\right) ; \\
g\left(\beta_{1}\right)\left\{(P(Q)+\alpha x-c) Q-\phi\left(\beta_{1}, x\right)\right\} \text { if } F=\phi\left(\beta_{1}, x\right) .
\end{array}
$$

Denote by $\beta_{D}(\alpha) \in\left\{\beta_{1}, \beta_{2}\right\}$ the critical level such that $\phi\left(\beta_{D}, x\right)=F$. Then, it is optimal for the distributor to choose the quality and the quantity that maximizes the profit

\footnotetext{
${ }^{8}$ An alternative would be that generic quality $x=0$ is produced with a zero profit for the producer. This would yield similar conclusions.
} 
$(P(Q)+\alpha x-c) Q-\phi\left(\beta_{D}, x\right)$. This is because as the fixed cost is only paid if the producer accepts to produce, the distributor captures the total profit generated by the "marginal" producer $\beta=\beta_{D}(\alpha)$. Given our assumption that $\Pi^{m}(\alpha, x)-\phi(\beta, x)$ is quasi-concave in $x$, the choice of characteristic is uniquely defined by

$$
x_{D}(\alpha)=x^{M}\left(\alpha, \beta_{D}(\alpha)\right)
$$

and the quantity is then $Q_{D}(\alpha) \equiv Q^{M}\left(\alpha, \beta_{D}(\alpha)\right)$. When production occurs, the allocation is thus the same as with an integrated monopoly having a cost $\phi\left(\beta_{D}(\alpha), x\right)$ and the profit is $V^{M}\left(\alpha, \beta_{D}(\alpha)\right)$. The choice of the fixed payment $F$ (and thus of $\beta_{D}$ ) then results from a choice between paying a high price and obtaining the good for sure and paying a low price at the risk of not obtaining the good. The distributor chooses the first option, $\beta_{D}(\alpha)=\beta_{2}$, whenever

$$
V^{M}\left(\alpha, \beta_{2}\right) \geq g\left(\beta_{1}\right) V^{M}\left(\alpha, \beta_{1}\right)
$$

which is the case if the likelihood of the efficient technology is not too large, more precisely if:

$$
\bar{g}_{1}(\alpha)=\frac{V^{M}\left(\alpha, \beta_{2}\right)}{V^{M}\left(\alpha, \beta_{1}\right)} \geq g\left(\beta_{1}\right)
$$

A sufficient condition for this to hold is that for all $x$ on the relevant range

$$
\left(\Pi^{m}(\alpha, x)-\phi\left(\beta_{2}, x\right)\right) \frac{1-g\left(\beta_{1}\right)}{g\left(\beta_{1}\right)}>\Delta(x) .
$$

where we recall that $\Delta(x) \equiv \phi\left(\beta_{2}, x\right)-\phi\left(\beta_{1}, x\right)$. We conclude that

Proposition 1 When the distributor owns the brand and the producer accepts the offer, the allocation is the same as if there were an integrated monopoly with the technology of the least efficient producer accepting the offer.

The distributor chooses to pay the high fixed cost if the cost differential $\Delta(x)$ is small or if the likelihood $g\left(\beta_{1}\right)$ of a small fixed cost is small.

One immediate consequence of the fact that the cost of quality perceived by the distributor is larger than the true one is thus that either there is under-production or the quality is distorted downward: 
Corollary 1 A distributor owning the brand provides lower quality than an integrated monopoly or no good at all.

Proof. If the producer accepts for all $\beta$, then $x_{D}(\alpha)=x^{M}\left(\alpha, \beta_{2}\right)<x^{M}\left(\alpha, \beta_{1}\right)$. Otherwise quality is $x_{D}(\alpha)=x^{M}\left(\alpha, \beta_{1}\right)$ when $\beta=\beta_{1}$ but it is not sold when $\beta=\beta_{2}$.

Thus the main cost of having distributor's ownership is that the quality choices will be distorted downward (case $F=\phi\left(\beta_{2}, x\right)$ ) or the good may not be produced (case $F=$ $\left.\phi\left(\beta_{1}, x\right)\right)$.

\section{The producer owns the brand}

We consider now the case where the producer has the control rights on the product. Suppose the producer has chosen quality $x$. Given that information about the demand is known only by the distributor, the producer will offer a non-linear contract to the distributor. We assume that the producer cannot monitor the retail price so that the contract is a wholesale non-linear tariff. From the revelation principle, for a given $x$, we can represent the contract at stage 3 as a menu $(Q(\alpha), T(\alpha))_{\alpha}$ designed so that the distributor chooses the option $(Q(\alpha), T(\alpha))$ when the demand shifter parameter is $\alpha$. The distributor obtains

$$
\Pi_{D}(\alpha)=(P(Q(\alpha))+\alpha x) Q(\alpha)-T(\alpha)
$$

where the truth-telling constraints write as

$$
\begin{aligned}
& \Pi_{D}\left(\alpha_{1}\right) \geq\left(P\left(Q\left(\alpha_{2}\right)\right)+\alpha_{1} x\right) Q\left(\alpha_{2}\right)-T\left(\alpha_{2}\right) \\
& \Pi_{D}\left(\alpha_{2}\right) \geq\left(P\left(Q\left(\alpha_{1}\right)\right)+\alpha_{2} x\right) Q\left(\alpha_{1}\right)-T\left(\alpha_{1}\right) .
\end{aligned}
$$

The profit of the producer (net of the fixed $\operatorname{cost} \phi(\beta, x))$ is then

$$
T(\alpha)-c Q(\alpha)=(P(Q(\alpha))+\alpha x-c) Q(\alpha)-\Pi_{D}(\alpha) .
$$

As the profit function $Q(P(Q)+\alpha x)$ is increasing in $\alpha$, the distributor's profit $\Pi_{D}(\alpha)$ is increasing in $\alpha$. Moreover the marginal benefit of increasing quality $x$ is increasing in $\alpha$ :

$$
\frac{\partial Q\left(P(Q)+\alpha_{2} x\right)}{\partial Q}=\alpha_{2} x>\frac{\partial Q\left(P(Q)+\alpha_{1} x\right)}{\partial Q}=\alpha_{1} x
$$


which is the standard sorting condition for the Principal-Agent problem where the producer acts as Principal and the distributor as Agent. Following standard methods from contract theory (see Salanié, 1997, or Laffont and Martimort, 2002), the optimal contract $(Q(\alpha), T(\alpha))$ proposed by the producer will satisfy incentive compatibility and individual rationality constraints if the following conditions hold:

$$
\begin{aligned}
I C & : \quad \Pi_{D}\left(\alpha_{2}\right)=x Q\left(\alpha_{1}\right)\left(\alpha_{2}-\alpha_{1}\right) ; \\
M \quad: \quad & Q\left(\alpha_{2}\right) \geq Q\left(\alpha_{1}\right) ; \\
P \quad: & \Pi_{D}\left(\alpha_{1}\right)=0 .
\end{aligned}
$$

The first constraint binds the incentive constraint of the high type distributor $\left(\alpha=\alpha_{2}\right)$ while the second states that the quantity increases with the type. The last constraint ensures participation of both types. We thus solve the maximization program (using (3)):

$$
\begin{aligned}
& \max _{\left(Q(\alpha), \Pi_{D}(\alpha)\right)} \sum_{i=1,2}\left\{\left(P\left(Q\left(\alpha_{i}\right)\right)+\alpha_{i} x-c\right) Q\left(\alpha_{i}\right)-\Pi_{D}\left(\alpha_{i}\right)\right\} f\left(\alpha_{i}\right) \\
& \text { s.t. } I C, M, P .
\end{aligned}
$$

Replacing $\Pi_{D}\left(\alpha_{1}\right)$ and $\Pi_{D}\left(\alpha_{2}\right)$ by their values and ignoring the monotonicity constraint $M$, we obtain the reduced program:

$$
\max _{Q\left(\alpha_{1}\right), Q\left(\alpha_{2}\right)}\left\{\begin{array}{c}
\left\{\left(P\left(Q\left(\alpha_{1}\right)\right)+\alpha_{1} x-c-\frac{f\left(\alpha_{2}\right)}{f\left(\alpha_{1}\right)}\left(\alpha_{2}-\alpha_{1}\right) x\right) Q\left(\alpha_{1}\right)\right\} f\left(\alpha_{1}\right) \\
+\left\{\left(P\left(Q\left(\alpha_{2}\right)\right)+\alpha_{2} x-c\right) Q\left(\alpha_{2}\right)\right\} f\left(\alpha_{2}\right)
\end{array}\right\}
$$

Let use define the new parameters

$$
\hat{\alpha}_{1}=\alpha_{1}-\frac{f\left(\alpha_{2}\right)}{f\left(\alpha_{1}\right)}\left(\alpha_{2}-\alpha_{1}\right) \text { and } \hat{\alpha}_{2}=\alpha_{2}
$$

This parameter measures the informational rent that has to be given (per unit of quality) to raise the production by one unit. With this notation, the optimal quantity for type $\alpha$ maximizes $(P(Q)+\hat{\alpha} x-c) Q$, which solves the monopoly Lerner condition:

$$
\frac{P\left(Q\left(\alpha_{i}\right)\right)+\hat{\alpha}_{i} x-c}{P(Q(\alpha))}=\frac{1}{\varepsilon\left(Q\left(\alpha_{i}\right)\right)} \Longleftrightarrow Q\left(\alpha_{i}\right)=Q^{m}\left(\hat{\alpha}_{i}, x\right) .
$$


The quantity $Q^{m}\left(\hat{\alpha}_{i}, x\right)$ is the monopoly quantity for virtual demand shifter $\hat{\alpha}$ instead of $\alpha$. The production is distorted downward compared to the case where $\alpha$ is known. The solution is monotonic in $\alpha$ so that the condition $M$ is satisfied.

Given the quantities $Q(\alpha)$ and the distributor's profit $\Pi_{D}\left(\alpha_{2}\right)=x Q\left(\alpha_{1}\right)\left(\alpha_{2}-\alpha_{1}\right)$ and $\Pi_{D}\left(\alpha_{1}\right)=0$, the producer's total profit is

$$
\sum_{i=1,2}\left\{\left(P\left(Q\left(\alpha_{i}\right)\right)+\alpha_{i} x-c\right) Q\left(\alpha_{i}\right)-\Pi_{D}\left(\alpha_{i}\right)\right\} f\left(\alpha_{i}\right)-\phi(\beta, x)
$$

which can be written from above as

$$
\begin{aligned}
& \max _{Q\left(\alpha_{1}\right), Q\left(\alpha_{2}\right)} \sum_{i=1,2}\left\{\left(P\left(Q\left(\alpha_{i}\right)\right)+\hat{\alpha}_{i} x-c\right) Q\left(\alpha_{i}\right)\right\} f\left(\alpha_{i}\right)-\phi(\beta, x) \\
= & \sum_{i=1,2} \Pi^{m}\left(\hat{\alpha}_{i}, x\right) f\left(\alpha_{i}\right)-\phi(\beta, x) .
\end{aligned}
$$

Using the envelop theorem, we obtain the equilibrium quality as the solution of the first-order condition:

$$
\begin{aligned}
\sum_{i=1,2} \hat{\alpha}_{i} Q_{P}\left(\alpha_{i}, \beta\right) f\left(\alpha_{i}\right) & =\frac{\partial \phi}{\partial x}\left(\beta, x_{P}(\beta)\right), \\
Q_{P}\left(\alpha_{i}, \beta\right) & =Q^{m}\left(\hat{\alpha}_{i}, x_{P}(\beta)\right) .
\end{aligned}
$$

We thus conclude that

Proposition 2 When the producer owns the brand, the allocation is the same as if there were an integrated monopoly facing a demand with (virtual) demand shifter $\hat{\alpha}$, choosing the characteristic $x$ knowing $\beta$ but not $\alpha$, then producing under full information .

For fixed quality levels, producer ownership introduces an agency problem leading to higher prices and lower quantities.

Regarding the level of quality, the comparison with full information is ambiguous. If the information on $\alpha$ were made public after the producer has designed the product, we would have $\hat{\alpha}_{1}=\alpha_{1}$ and $x^{M}\left(\alpha_{1}, \beta\right)<x_{P}(\beta)<x^{M}\left(\alpha_{2}, \beta\right)$. This reflects the fact that the producer designs the product before knowing the demand characteristic. To this we must add two effects. But the producer's incentives to invest are hindered by the necessity to leave an 
informational rent to the distributor which leads to a reduction of the quality level for all values of $\beta$.

The comparison between the quality choice of a producer-owner and a distributor-owner is also ambiguous. The producer perceives the true cost of quality so that investment may be higher than with distributor's ownership when $\beta=\beta_{1}$, but the distributor is more efficient when deciding production which raises the marginal benefits of raising quality.

\section{Brand ownership and distributor's information}

We now address the issue of brand ownership. To discuss whether the brand should be owned by the distributor of by the producer, we compare total profit in the two previous cases. The interpretation is the following. There is some ex-ante stage at which the parties can agree on whether the retailer will distribute its own brand or the brand of the producer. At this stage, contracts are incomplete so that only brand ownership can be decided upon. But the two parties can still agree on some ex-ante transfer as a compensation for not owning the brand distributed. In this context they will choose the ownership structure that maximizes total profit accounting for the fact that the owner will gain decision rights.

Our objective is to determine how the quality of the distributor's information affects the optimal allocation of ownership. In order to better assess the impact of information on brand ownership, we model more explicitly how this information is determined by considering the following model.

Suppose that the true demand shifter can take two values, that we normalize to be $\mu-\frac{1}{2}$ or $\mu+\frac{1}{2}$, with equal probabilities, where $\mu \geq 3 / 2$. It is never observed but the distributor observes a signal $s$ that can take the same two values: the signal takes the same value as the true demand shifter with probability $1 / 2+\gamma>1 / 2$, where $\gamma \in[0,1 / 2]$ while it takes the other value with probability $1 / 2-\gamma$ (irrespective of the true value). Let $\alpha_{1}$ be the expected value of the demand shifter given the signal $s=\mu-\frac{1}{2}$ and $\alpha_{2}$ be the expected value of the demand shifter given the signal $s=\mu+\frac{1}{2}$. Given linearity in $\alpha$ of the inverse demand curve, 
we have an expected price $P(Q)+\alpha_{i} x$. Thus, this induces expected demand shifter in our model:

$$
\alpha_{1}=\mu-\gamma, \alpha_{2}=\mu+\gamma, \text { with } f\left(\alpha_{1}\right)=f\left(\alpha_{2}\right)=\frac{1}{2} .
$$

As $\gamma$ increases, the distributor's information varies from no information to perfect knowledge of the true demand shifter.

We denote by $V_{P}$ the total industry profit when the producer owns the brand and the precision of the distributor's information is $\gamma$. It is given by (using the fact that $\alpha_{2}-\alpha_{1}=2 \gamma$ ):

$$
V_{P}=\sum_{j=1,2}\left\{\frac{1}{2} \sum_{i=1,2} \Pi^{m}\left(\hat{\alpha}_{i}, x_{P}\left(\beta_{j}\right)\right)-\phi\left(\beta_{j}, x_{P}\left(\beta_{j}\right)\right)+\gamma x_{P}\left(\beta_{j}\right) Q^{m}\left(\hat{\alpha}_{1}, x_{P}\left(\beta_{j}\right)\right)\right\} g\left(\beta_{j}\right),
$$

where $\hat{\alpha}_{1}=\mu-3 \gamma$ and $\hat{\alpha}_{2}=\mu+\gamma$

The producer obtains the monopoly profit for the virtual demand shifter. To this we add the informational rent of the agent.

For $\gamma=0$, the distributor has no information and we find that $V_{P}$ is equal to the aggregate monopoly profit. Moreover $V_{D}$ is smaller than the monopoly profit because the distributor doesn't design the product optimally. Thus $V_{D}<V_{P}$ when $\gamma=0$. In other words, if the distributor has no information, the producer should own the brand.

Lemma 1 Producer ownership generates more aggregate profits than distributor ownership if the distributor's information is imprecise enough, i.e. if $\gamma$ is small enough.

The question is thus whether distributor ownership may dominate if the distributor information is precise.

The total profit $V_{D}$ when the distributor owns the brand depends on whether the distributor chooses to pay the high fixed cost or the low fixed cost. For conciseness we first consider the case where the distributor always chooses to produce the good.

Assumption 1: For all $\alpha \in[1,2]$, we have $\bar{g}_{1}(\alpha) \geq g\left(\beta_{1}\right)$. 
Notice that this is the case if (2) holds for any $\alpha \in[1,2]$. In this case, allocating the ownership to the distributor never results in no production of the good but in under-provision of quality. As a result the total profit under distributor ownership is given by

$$
V_{D}=\sum_{i=1,2} \frac{1}{2}\left\{V^{M}\left(\alpha_{i}, \beta_{2}\right)+\Delta\left(x_{D}\left(\alpha_{i}\right)\right) g\left(\beta_{1}\right)\right\}
$$

The interpretation is the following: the distributor acts as if the technology is inefficient and obtains $\Pi^{M}\left(\alpha, \beta_{2}\right)$. To this benefit we add the cost saving that occurs when the technology is efficient.

Clearly, if $\beta$ is known, total profit is maximal when the distributor owns the brand. ${ }^{9} \mathrm{We}$ now assume that $g\left(\beta_{1}\right)>0$.

On the other extreme, with precise distributor's information ( $\gamma$ is large), the comparison between $V_{P}$ and $V_{D}$ depends on the relative value of each agent's information. We can measure the value of the distributor's information by its value for an integrated monopoly with fixed cost parameter $\beta$. Formally this is defined as

$$
\delta(\beta, \gamma)=\sum_{i=1,2} \frac{1}{2} V^{M}\left(\alpha_{i}, \beta\right)-\max _{x}\left\{\sum_{i=1,2} \frac{1}{2} \Pi^{m}\left(\alpha_{i}, x\right)-\phi(\beta, x)\right\} .
$$

It corresponds to the value for the integrated industry of learning the information about demand before choosing the design that maximizes total profit. It is thus an upper bound on the value of information under symmetric information. The value $\delta$ is increasing with $\gamma$.

On the other hand, the value of the information of the producer comes from the fact that the vertical structure can adjust the investment in quality depending on the efficiency of the technology. This value increases when the cost differential becomes larger.

Proposition 3 Under assumption 1, distributor ownership generates more aggregate profits than producer ownership if

$$
\delta\left(\beta_{2}, \gamma\right)>\left[\Delta\left(x^{M}\left(\mu+\frac{1}{2}, \beta_{1}\right)\right)-\Delta\left(x^{M}\left(\mu-\frac{1}{2}, \beta_{2}\right)\right)\right] g\left(\beta_{1}\right) .
$$

\footnotetext{
${ }^{9}$ In this case, we have $g\left(\beta_{1}\right)=0$ for assumption 1 to hold.
} 
Proof. see appendix

Thus if the asymmetry of information on costs is not too large, distributor ownership will generate more profit in aggregate than producer ownership. The reason is that distributor ownership better exploits the distributor's information by avoiding the quantity distortion when demand is high. Thus if the asymmetry of information on the product cost is not too large, it will be more profitable to accept a suboptimal design under distributor ownership than a suboptimal supply under producer ownership.

Notice that the asymmetry of information on costs can be small either because $\Delta$ is small, in which case the information is not important, or because $g\left(\beta_{1}\right)$ is small, so that information not too imprecise.

Consider now the case where the distributor would always propose to pay only the small fixed cost. This occurs when

Assumption 2: For all $\alpha \in[1,2]$, we have $\bar{g}_{1}(\alpha)<g\left(\beta_{1}\right)$.

Then distributor ownership results in under-production and

$$
V_{D}=\left\{\frac{1}{2} V^{M}\left(\mu-\gamma, \beta_{1}\right)+\frac{1}{2} V^{M}\left(\mu+\gamma, \beta_{1}\right)\right\} g\left(\beta_{1}\right) .
$$

Here the distributor obtains the full integrated profit but only when the technology is efficient.

Again if $\beta$ is known, total profit is maximal when the distributor owns the brand. ${ }^{10} \mathrm{We}$ assume that $g\left(\beta_{1}\right)<1$. For $\gamma=0$, recall that $V_{P}$ is larger than $V_{D}$ as above although now it is because distributor ownership induces under-production rather than under-investment. The analysis then leads to a similar conclusion:

Proposition 4 Under assumption 2, distributor ownership generates more aggregate profits than producer ownership if

$$
\delta\left(\beta_{1}, \gamma\right)>V^{M}\left(\mu+\frac{1}{2}, \beta_{2}\right) \frac{1-g\left(\beta_{1}\right)}{g\left(\beta_{1}\right)} .
$$

\footnotetext{
${ }^{10}$ In this case, we have $g\left(\beta_{1}\right)=1$ for assumption 2 to hold.
} 
Proof. see appendix

We see again that when the value of the distributor's information is large, it is optimal to give ownership to the distributor whenever he has precise information.

From the two cases we conclude that it is optimal to give ownership to the distributor when the value of his information is large enough or when there is little uncertainty on the fixed cost.

\subsection{The linear-quadratic model}

To gain more insight, we now discuss the effect of the precision of the distributor's information on profit in a more parametric model. To this purpose, let us consider the case where demand is linear and the cost is quadratic. To fix ideas and focus on the effect of the information we fix all parameters and vary $\gamma$ and $\beta_{2}$. We thus have:

$$
P(Q)=1-Q ; \phi(\beta, x)=\beta \frac{x^{2}}{2} ; c=0 ; \frac{1}{2}\left(\mu+\frac{1}{2}\right)^{2}<\beta_{1}<\beta_{2}, ; g\left(\beta_{i}\right)=\frac{1}{2}
$$

Moreover for what follows, we will assume

$$
\mu=1.5, \quad \beta_{1}=3
$$

and let vary $\beta_{2}$ between 3 and 6 . For the linear-quadratic model we find

$$
\Pi^{m}(\alpha, x)=\left(\frac{1+\alpha x}{2}\right)^{2} \text { and } Q^{m}(\alpha, x)=\frac{1+\alpha x}{2},
$$

which yields the integrated monopoly profit and allocation:

$$
V^{M}(\alpha, \beta)=\frac{1}{2} \frac{\beta}{2 \beta-\alpha^{2}} ; \quad Q^{M}(\alpha, \beta)=\frac{\beta}{2 \beta-\alpha^{2}} \quad \text { and } \quad x^{M}(\alpha, \beta)=\frac{\alpha}{2 \beta-\alpha^{2}} .
$$

When the producer owns the brand, the above analysis implies that we have

$$
x_{P}(\beta)=\frac{\frac{1}{2} \sum_{i=1,2} \hat{\alpha}_{i}}{2 \beta-\frac{1}{2} \sum_{i=1,2} \hat{\alpha}_{i}^{2}}=\frac{\mu-\gamma}{2 \beta-\mu^{2}+2 \mu \gamma-10 \gamma^{2}} .
$$

One can verify that 
Lemma 2 For $\beta \in\left(3, \frac{41}{8}\right), x_{P}(\beta)$ decreases then increases when the distributor's information becomes more precise. For larger $\beta$, it is decreasing.

Proof. The slope of $x_{P}$ is $-\frac{10 \gamma^{2}-20 \gamma \mu+\mu^{2}+2 \beta}{\left(-10 \gamma^{2}+2 \gamma \mu-\mu^{2}+2 \beta\right)^{2}}$. Then $10 \gamma^{2}-20 \gamma \mu+\mu^{2}+2 \beta$ decreases with $\gamma$ from $(1.5)^{2}+2 \beta>0$ to $\frac{5}{2}-10 \mu+\mu^{2}+2 \beta$. Finally $\frac{5}{2}-10 \mu+\mu^{2}+2 \beta=-\frac{41}{4}+2 \beta$ is negative for $\beta>5.125$.

Thus better retailer information reduces the quality investment at least when the cost is large. The total industry profit is then

$$
V_{P}=\sum_{j=1,2} \frac{1}{4}\left\{\frac{1}{2}+\frac{1}{2} \frac{(\mu+\gamma)(\mu-\gamma)}{2 \beta_{j}-\mu^{2}+2 \mu \gamma-10 \gamma^{2}}+\frac{\gamma(\mu-3 \gamma)(\mu-\gamma)^{2}}{\left(2 \beta_{j}-\mu^{2}+2 \mu \gamma-10 \gamma^{2}\right)^{2}}\right\}
$$

which may not be monotonic in $\gamma$. The sign of the derivative of $V_{P}$ is ambiguous as it captures two effects. On the one hand the information of the distributor is valuable as it allows to better match supply with demand. On the other hand, asymmetric information implies distortions in the product design and supply that are costly.

Consider now the case where the distributor owns the brand. Then $\bar{g}_{1}(\alpha)=\frac{\beta_{2}}{\beta_{1}} \frac{2 \beta_{1}-\alpha^{2}}{2 \beta_{2}-\alpha^{2}}$ is decreasing in $\alpha$. Thus production always occurs when $\bar{g}_{1}\left(\mu+\frac{1}{2}\right) \geq \frac{1}{2}$ (the distributor pays the high fixed cost for any information). We focus the comparison on this range. Then the industry value is

$$
\begin{aligned}
V_{D} & =\sum_{i=1,2} \frac{1}{4}\left(\frac{\beta_{2}}{2 \beta_{2}-\alpha_{i}^{2}}+\frac{\beta_{2}-\beta_{1}}{2}\left(\frac{\alpha_{i}}{2 \beta_{2}-\alpha_{i}^{2}}\right)^{2}\right) \\
\text { where } \alpha_{1} & =\mu-\gamma \text { and } \alpha_{2}=\mu+\gamma
\end{aligned}
$$

The value $V_{D}$ is increasing in $\gamma$ by convexity of the profit in $\alpha \cdot{ }^{11}$

Consider parameters $\mu=\frac{3}{2}$ and $\beta_{1}=3$. When $\beta_{2}$ varies from 3 to 6 , we can verify that $\bar{g}_{1}(2)>\frac{1}{2}$. We plot below the value functions under producer ownership and under

\footnotetext{
${ }^{11}$ Similarly when $\bar{g}_{1}\left(\mu-\frac{1}{2}\right)<g\left(\beta_{1}\right)$ we have $V_{D}=\frac{1}{4} \frac{\beta_{1} / 2}{2 \beta_{1}-(\mu-\gamma)^{2}}+\frac{1}{4} \frac{\beta_{1} / 2}{2 \beta_{1}-(\mu+\gamma)^{2}}$.

When $\bar{g}_{1}\left(\mu+\frac{1}{2}\right)<g\left(\beta_{1}\right) \leq \bar{g}_{1}\left(\mu-\frac{1}{2}\right)$ and $\gamma$ is large, we have $V_{D}=$ $\frac{1}{4}\left(\frac{\beta_{2}}{2 \beta_{2}-(\mu-\gamma)^{2}}+\frac{\beta_{2}-\beta_{1}}{2}\left(\frac{\mu-\gamma}{2 \beta_{2}-(\mu-\gamma)^{2}}\right)^{2}\right)+\frac{1}{4} \frac{\beta_{1} / 2}{2 \beta_{1}-(\mu+\gamma)^{2}}$.
} 
distributor ownership (dotted lines) for different values of $\beta_{2}$. The plots of the value functions then show that the two curves cross only once and that distributor's ownership generates more aggregate profit for $\gamma$ above a threshold when $\beta_{2}<5$.
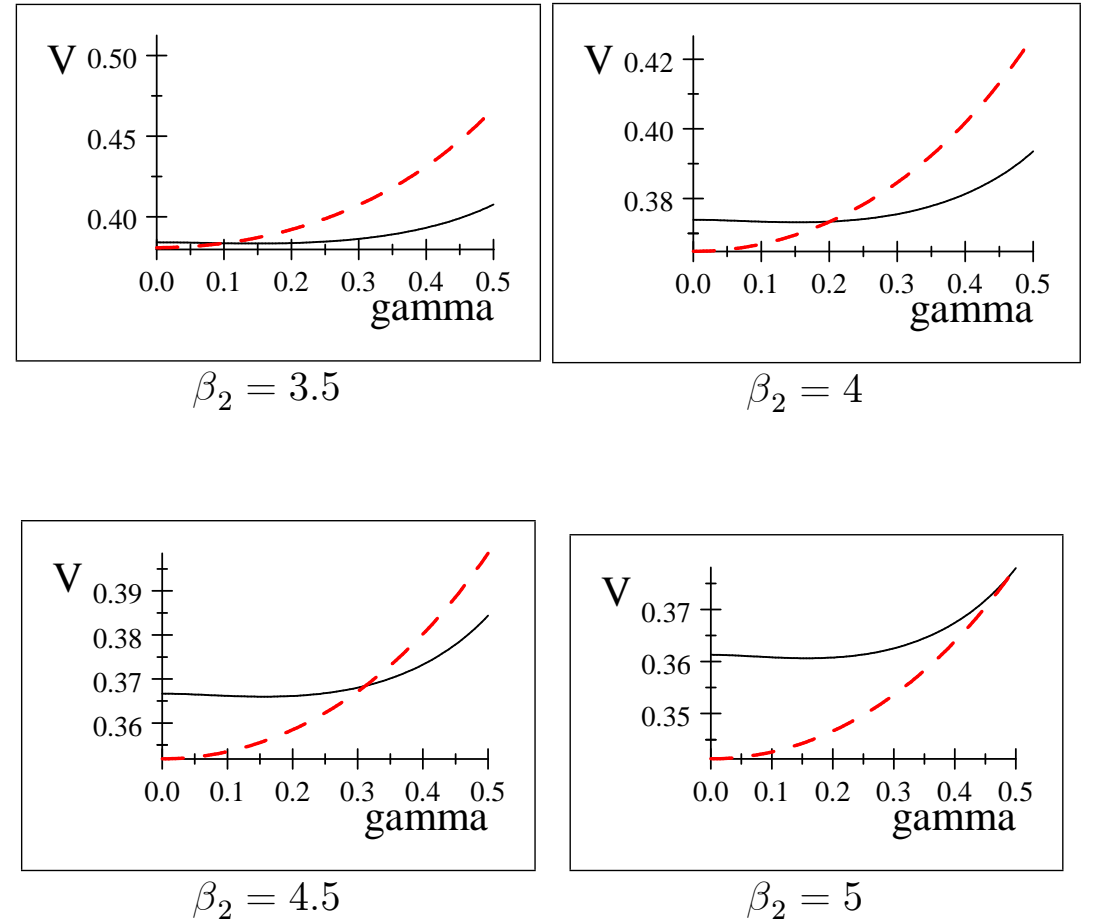

\section{When ownership does not give bargaining power}

We have assumed so far that due to the nature of branded products (their necessity) in the large distribution, the owner of the brand had a large bargaining. We discuss briefly the case where the owner of the brand has the right to design the product but has no bargaining power.

Consider the case where the producer owns the brand, but once $x$ is chosen the distributor offers a contract on a take-it or leave it basis. The game has to be analyzed as a signalling game, where the choice of product characteristic signals the type of the producer. It is then immediate to see that given that revealing himself as having a low costs would result in no rent in the contracting stage, the only equilibria of this signalling games are pooling 
equilibria. The choice of characteristic $x$ is the same for both values of $\beta$. Then there is a continuum of equilibria. Given $x$, the distributor then chooses the monopoly quantity and would cover the fixed cost $\phi\left(\beta_{2}, x\right)$.

A similar argument would show that if the distributor were to choose $x$, while the producer chooses the contract, then the choice of $x$ would be the same for $\alpha_{1}$ and $\alpha_{2}$. The contract would then be designed as in the case above of production ownership.

Thus when decision rights on product characteristics do not convey some bargaining power, the result is that the decision becomes non-reactive to any information. From the vertical structure perspective, this is suboptimal, as no information is used to optimize the product design stage.

\section{Conclusion}

Our paper shows that the most profitable ownership structure for brands depends on the information structure. Whenever distributors have access to a superior information for branding strategies, it may be more profitable to have these choices delegated to the distributors. We have assumed that negotiations on ownership were done with no distortions, but the incentives of the distributor to introduce its own brand should be higher under imperfect bargaining over ownership. This is because, the distributor would have to care about the bargaining power that ownership would give to the producer.

The paper thus illustrates the fact that one element that may explain the recent trend towards the introduction by distributors of their own label, is the development of information technologies that has dramatically raised the amount of information that large distribution chains can collect and treat. As information improves in the downstream part of the market, then it becomes more profitable for the distributor to introduce its private label, rather than to continue to distribute producers' labels. This argument requires however to admit that the distributor is in a good position to impose its new label and thus can leverage reputation effects. Thus the argument is just one part of the story and is complementary to others 
arguments that can be advanced (as reputation effects, lower costs for in store promotion campaign..).

In terms of welfare, the effect of introducing the distributor private label is ambiguous. Distributors typically under-invest in quality in our model. With producer's brand ownership, there may be less or more under-investment, while there is a double marginalization problem due to the necessity to leave an informational rent to the distributor. Thus one cannot assess a priori whether the introduction of distributor labels reduces or raises consumers' welfare.

\section{References}

[1] Berges-Sennou F., Bontems P. and V. Réquillart, (2004), "Economics of Private Labels: A Survey of the Literature", Journal of Agricultural and Food Industrial Organization, vol. 2 , art. 3 .

[2] Bontemps, C., Orozco, V., and V. Réquillart, V. (2008). "Private labels, national brands and food prices", Review of Industrial Organization, 33(1), 1-22.

[3] Chintagunta, P. K., A. Bonfrer and I. Song, (2002), "Investigating the Effects of Store Brand Introduction on Retailer Demand and Pricing Behavior," Management Science, 48, 10, 2002.

[4] Comanor W. and P. Rey (2000) "Vertical Restraints and the Market Power of Large Distributors", Review of Industrial Organization, 17(2):135-153

[5] Connor J. M. and E. B. Peterson "Market-Structure Determinants of National BrandPrivate Label Price Differences of Manufactured Food Products" The Journal of Industrial Economics, Vol. 40, No. 2. pp. 157-171.

[6] Cotterill, R. W., W. P. Putsis, and R. Dhar (2000), "Assessing the Competitive Interaction between Store brands and National Brands," Journal of Business, Vol. 73, No.1, 109-137. 
[7] Dessein, W. (2002). "Authority and communication in organizations", The Review of Economic Studies, 69(4), 811-838.

[8] Gabrielsen, T. S., and L. Sørgard, (2007), "Private labels, price rivalry, and public policy", European Economic Review, 51(2), 403-424.

[9] Grossman, S.J. and Hart, O.D., (1986), "The costs and benefits of ownership: A theory of vertical and lateral integration", The Journal of Political Economy, pp.691-719.

[10] Kadiyali, V., N. Vilcassim, and P. K. Chintagunta (2000), "Power in ManufacturerRetailer Interactions: An Empirical Investigation of Pricing in a Local Market," Marketing Science, 19, 2, 127-148.

[11] Laffont J.J. and D. Martimort (2002): The Theory of Incentives, Princeton University Press.

[12] Meza, S. and K. Sudhir (2010). "Do private labels increase retailer bargaining power?", Quantitative Marketing and Economics, 8(3), 333-363.

[13] Mills D. E. (1995) "Why Retailers Sell Private Labels," Journal of Economics and Management Strategy 4 509-528.

[14] Salanié B. (1997): The Economics of Contracts: A Primer, MIT Pres.

[15] Schmalensee R. (1982) "Product Differentiation Advantages of Pioneering Brands", The American Economic Review, Vol. 72, No. 3. , pp. 349-365.

[16] Scott Morton F. and F. Zettelmeyer (2004) "The Strategic Positioning of Store Brands in Retailer-Manufacturer Bargaining" The Review of Industrial Organization, 24(2), 161-194. 


\section{A Appendix}

Proof of proposition 3. Notice that the expected variable profit of the producer is

$$
\frac{1}{2} \Pi^{m}(\mu-3 \gamma, x)+\frac{1}{2} \Pi^{m}(\mu+\gamma, x)=\Pi^{m}(\mu-\gamma, x)
$$

Thus

$$
\begin{aligned}
V_{P}= & \left\{\max _{x}\left\{\frac{1}{2} \Pi^{m}(\mu-3 \gamma, x)+\frac{1}{2} \Pi^{m}(\mu+\gamma, x)-\phi\left(\beta_{2}, x\right)\right\}+\frac{1}{2} x_{P}(\beta) Q^{m}\left(\mu-3 \gamma, x_{P}\left(\beta_{2}\right)\right)\right\} g\left(\beta_{2}\right) \\
& +\left\{\max _{x}\left\{\frac{\Pi^{m}(\mu-3 \gamma, x)}{2}+\frac{\Pi^{m}(\mu+\gamma, x)}{2}-\phi\left(\beta_{1}, x\right)\right\}+\frac{1}{2} x_{P}(\beta) Q^{m}\left(\mu-3 \gamma, x_{P}\left(\beta_{1}\right)\right)\right\} g\left(\beta_{1}\right)
\end{aligned}
$$

But

$$
\begin{aligned}
& \max _{x}\left\{\frac{1}{2} \Pi^{m}(\mu-3 \gamma, x)+\frac{1}{2} \Pi^{m}(\mu+\gamma, x)-\phi(\beta, x)\right\}+\frac{1}{2} x_{P}(\beta) Q^{m}\left(\mu-3 \gamma, x_{P}(\beta)\right) \\
< & \max _{x}\left\{\frac{\Pi^{m}(\mu-\gamma, x)}{2}+\frac{\Pi^{m}(\mu+\gamma, x)}{2}-\phi(\beta, x)\right\}
\end{aligned}
$$

Therefore

$$
\begin{aligned}
V_{P}< & g\left(\beta_{2}\right) \max _{x}\left\{\frac{\Pi^{m}(\mu-\gamma, x)}{2}+\frac{\Pi^{m}(\mu+\gamma, x)}{2}-\phi\left(\beta_{2}, x\right)\right\} \\
& +g\left(\beta_{1}\right) \max _{x}\left\{\frac{\Pi^{m}(\mu-\gamma, x)}{2}+\frac{\Pi^{m}(\mu+\gamma, x)}{2}-\phi\left(\beta_{2}, x\right)+\Delta(x)\right\}
\end{aligned}
$$

Using the fact that $x$ is smaller than $x^{M}\left(\mu+\frac{1}{2}, \beta_{1}\right)$ in all cases, we have

$$
V_{P}<\max _{x}\left\{\frac{\Pi^{m}(\mu-\gamma, x)}{2}+\frac{\Pi^{m}(\mu+\gamma, x)}{2}-\phi\left(\beta_{2}, x\right)\right\}+\Delta\left(x^{M}\left(\mu+\frac{1}{2}, \beta_{1}\right)\right) g\left(\beta_{1}\right) .
$$

Moreover

$$
\begin{aligned}
V_{D}= & \frac{1}{2}\left\{V^{M}\left(\mu-\gamma, \beta_{2}\right)+\Delta\left(x_{D}(\mu-\gamma)\right) g\left(\beta_{1}\right)\right\} \\
& +\frac{1}{2}\left\{V^{M}\left(\mu+\gamma, \beta_{2}\right)+\Delta\left(x_{D}(\mu+\gamma)\right) g\left(\beta_{1}\right)\right\} .
\end{aligned}
$$

Using the fact that $x$ is larger than $x^{M}\left(\mu-\frac{1}{2}, \beta_{2}\right)$

$$
V_{D}>\frac{1}{2} V^{M}\left(\mu-\gamma, \beta_{2}\right)+\frac{1}{2} V^{M}\left(\mu+\gamma, \beta_{2}\right)+\Delta\left(x^{M}\left(\mu-\frac{1}{2}, \beta_{2}\right)\right) g\left(\beta_{1}\right) .
$$


Then we find

$$
V_{D}-V_{P}>\delta\left(\beta_{2}, \gamma\right)-\left[\Delta\left(x^{M}\left(\mu+\frac{1}{2}, \beta_{1}\right)\right)-\Delta\left(x^{M}\left(\mu-\frac{1}{2}, \beta_{2}\right)\right)\right] g\left(\beta_{1}\right)
$$

Thus $V_{P}<V_{D}$ for $\delta\left(\beta_{2}, \gamma\right)>\left(\Delta\left(x^{M}\left(\mu+\frac{1}{2}, \beta_{1}\right)\right)-\Delta\left(x^{M}\left(\mu-\frac{1}{2}, \beta_{2}\right)\right)\right) g\left(\beta_{1}\right)$.

Proof of proposition 4 . We have

$$
V_{P}<\sum_{\beta \in\left\{\beta_{1}, \beta_{2}\right\}} \max _{x}\left\{\frac{\Pi^{m}(\mu-\gamma, x)}{2}+\frac{\Pi^{m}(\mu+\gamma, x)}{2}-\phi(\beta, x)\right\} g(\beta)
$$

and

$$
\begin{aligned}
V_{D} & =\left\{\frac{1}{2} V^{M}\left(\mu-\gamma, \beta_{1}\right)+\frac{1}{2} V^{M}\left(\mu+\gamma, \beta_{1}\right)\right\} g\left(\beta_{1}\right) \\
& =\max _{x}\left\{\frac{\Pi^{m}(\mu-\gamma, x)}{2}+\frac{\Pi^{m}(\mu+\gamma, x)}{2}-\phi\left(\beta_{1}, x\right)\right\} g\left(\beta_{1}\right)+\delta\left(\beta_{1}\right) g\left(\beta_{1}\right) .
\end{aligned}
$$

This implies that

$$
\begin{aligned}
V_{P}-V_{D} & <\max _{x}\left\{\frac{\Pi^{m}(\mu-\gamma, x)}{2}+\frac{\Pi^{m}(\mu+\gamma, x)}{2}-\phi\left(\beta_{2}, x\right)\right\} g\left(\beta_{2}\right) g\left(\beta_{2}\right)-\delta\left(\beta_{1}\right) g\left(\beta_{1}\right) \\
& <V^{M}\left(\mu+\frac{1}{2}, \beta_{2}\right) g\left(\beta_{2}\right)-\delta\left(\beta_{1}, \gamma\right) g\left(\beta_{1}\right) .
\end{aligned}
$$

Therefore when $V^{M}\left(\mu+\frac{1}{2}, \beta_{2}\right) g\left(\beta_{2}\right) \leq \delta\left(\beta_{1}, \gamma\right) g\left(\beta_{1}\right)$, it must be the case that $V_{P}<V_{D}$. 